\title{
Zoning assessment of water environmental supporting capacity for socioeconomic development in the Huaihe River Basin, China
}

\author{
ZHOU Liang ${ }^{1}$, "SUN Dongqi ${ }^{2}, \mathrm{XU}$ Jiangang $^{3}$
}

1. School of Geographic and Oceanographic Sciences, Nanjing University, Nanjing 210093, China;

2. Institute of Geographic Sciences and Natural Resources Research, CAS, Beijing 100101, China;

3. School of Architecture and Urban Planning, Nanjing University, Nanjing 210093, China

\begin{abstract}
There have been substantial conflicts in the human-water relationship in the Huaihe River Basin (HRB). To achieve sustainable economic development without degrading the water environment in the HRB, we develop a three-dimensional water environmental supporting capacity (WESC) model based on water environmental carrying capacity (WECC), water environmental pressure (WEP), and water pollution prevention and control capacity (WPPC). Geographic information systems spatial analysis with the analytical hierarchy process method and dynamic weighted summation is applied. Several proposals for suitable locations for industry and environmental protection strategies for water were presented. The following results were obtained. (1) The spatial differences in WECC are substantial; areas with high-value WECC zones are mainly located along the main stream of the Huaihe River on the south side. WEP is generally high, with an overall low level of pollution prevention and control in the whole HRB. WPPC and WEP show high spatial overlapping due to the fact that areas with higher environmental pollution usually have high level of economic development, and thus have a strong capacity for pollution control. (2) Overall, WESC is moderate in the HRB. In particular, areas with a high WESC value only account for $56.24 \%$ of the HRB in 2010 . Distinct differences in WESC also exist between areas located in the south compared with in the north of the basin, and areas alongside the downstream region compared with alongside the upstream and midstream regions. (3) Consequently, according to the guidance for industry zoning in the HRB, the areas in the south and alongside the downstream and sub-streams with a low WEP value and high WECC and WPPC, traditional industries should be developed based on strict environmental access and pollution emission standards. While for the areas along the midstream of the HRB and along the whole Yishusi River Basin, which have a high WEP value, industrial restructuring and technological upgrading are suggested. Action should be taken to limit development and protect the environment in the upstream region of the basin, which is a key source of drinking water, in the eastern route along the line of the South-to-
\end{abstract}

Received: 2014-11-15 Accepted: 2015-04-28

Foundation: National Science and Technology Major Project, No.2009ZX07210-010; Supported by Program B for Outstanding PhD Candidate of Nanjing University

Author: Zhou Liang (1983-), PhD Candidate, specialized in regional development and environmental geography. E-mail: zhougeo@126.com

"Corresponding author: Sun Dongqi (1985-), PhD, E-mail: sundongqi1985@outlook.com 
North Water Diversion Project, and in the ecologically fragile region alongside the basin. This will ensure good environmental functionality including subsistent provision of clean water, while at the same time satisfying the urgent need to adjust, transform, and upgrade the industrial structure.

Keywords: Huaihe River Basin; socioeconomic development; supporting capacity; 3D model; water environment

\section{Introduction}

Water is an important resource that is essential to basin development. Therefore, the quality of the water environment directly affects the rate and features of basin development. With the acceleration of urbanization, industrialization, and agricultural modernization, the emission load of water pollution has been increasing sharply, whereas the quality of the water degrading rapidly. Given these circumstances, key Chinese basins are severely affected by water environmental pollution across the world (Dong et al., 2014; Ouyang et al., 2006; Ren et al., 2014). The Chinese government has consistently implemented long-term measures to manage these urgent concerns. However, the overall worsening trends in water pollution in basin areas have not been effectively contained. The severe problems with water pollution have also weakened the economic development of the water environment, making it a bottleneck for the sound development of basins (Jiang, 2009; Nian et al., 2014; Zuo et al., 2014). The Huaihe River Basin (HRB) is one of the most densely populated areas with a large grain production capacity, and the core ability to undertake industrial transfer. As one of the basins with the greatest human-water conflicts, the HRB has witnessed numerous serious water environmental issues, the longest treatment processes, and highest cancer incidence (Tian et al., 2013; Yang and Zhuang, 2014a, 2014b; Zhang et al., 2014). The basin has a dual water cycle and the use of water resources and the relationship between the cycle and development are complex. Moreover, the increase in the social water cycle flux takes up almost all the natural runoff, and the water quality is worsened further by industry, agriculture, and domestic sewage. Currently, basin eco-compensation (Xie et al., 2013; Zhang et al., 2012), water rights trading (De Mouche et al., 2011), emission trading (Tong et al., 2009), enterprise pollution transfer (Cai, 2008; Li et al., 2013), clean production, and other mechanisms have not been fully established. Adjustment of the industrial structure, pollution control, and governmental environment monitoring system are incomplete, and the management, protection, and development of the basin water environment lack systematic guidance and overall design (Xia et al., 2011). More seriously, the threshold for environmental access in the Yangtze River Delta has increased for the past few years, resulting in a large number of high-pollution enterprises, such as textiles, dyeing and printing, rubber, plastics, and petrochemical engineering, in the HRB, pollution industry transfer from the developed areas to the nearby underdeveloped areas (Zhao and Jiang, 2013). Meanwhile, agriculture in the basin has reached its extreme output limit because farmers disproportionately use pesticides, fertilizers, mulching film, and other chemicals to increase production. This has resulted in a huge excess of ammonia nitrogen in surface water, causing serious nonpoint source pollution in the basin (Zhang and Huang, 2011; Zhou et al., 2013). Extensive development, industrial pollution transfer, extreme agricultural growth, and a surge in nonpoint source pollution are the most recent challenges experienced by the basin. However, identifying and regulating geographical sources of pollution is difficult. 
The Huaihe River is generally regarded as the geographical dividing line between northern and southern China, and shows distinct spatial differences in geomorphic features, ecology, assimilative capacity, water quality goals, and water environmental pressure (WEP). The development priorities of industries in this basin are also distinct. If the water environment constraints, WEP, and industrial controls are not considered, the water quality of the basin will deteriorate rapidly because the pollution load exceeds the water environmental capacity. Moreover, the self-purification and supply capacities of the water resource will also be damaged (Sun et al., 2011). Therefore, proper control and management of water resources is the scientific bases for protecting the basin environment and optimizing industrial development, and thus become a major focus of research worldwide. Numerous scientific publications and international journals have explored this subject matter, and the United States Environmental Protection Agency (EPA), European Union, and World Wide Fund for Nature continuously analyze and emphasize the importance of research in this field. In 1987, the EPA proposed the concept of water eco-function zoning. In particular, the EPA proposed eco-zoning of rivers, lakes, and other bodies of fresh water to form a three-pronged management system based on water eco-environment zoning. The system is designed to maintain, protect, and restore the integrity of the water environment and water eco-systems by conducting joint consultations and supervision among the interested parties (McMahon et al., 2001; Omernik, 1987). In 2000, the European Commission established the Water Framework Directive, which categorized surface water into rivers, lakes, transitional waters, and coastal waters, and extended the zoning classification system to water eco-systems in order to protect the water environment and manage water resources (Hering et al., 2010; Kallis and Butler, 2001). The UK, Denmark, Greece, and other countries investigated zoning of the water environment according to their national management demands on water resources to coordinate the demands of governmental water management departments, public participation, water volume, water quality, and aquatic ecology (Mylopoulos and Kolokytha, 2008; Singh et al., 2008; Snelder and Biggs, 2002; Soendergaard et al., 2005). In China, national water resource zoning, eco-hydrology zoning (Yang et al., 2008), function zoning of the water environment (Xia, 1989), water environmental carrying capacity (WECC) of water resources, and the support for forced zoning have been assessed since 1980. The complete zoning and management assessment system for basin water resources, water ecology, and water environment play a key role in the use of basin water resources, protecting the water environment, and regional economic development ( $\mathrm{Li}$ and $\mathrm{Li}, 2012$; Wang and $\mathrm{Zhu}, 2002$; Wang et al., 2000; Zhou et al., 2007). However, the literature on Chinese water environment zoning mainly deals with bodies of water, in which the majority of the assessment indicators are environmental background factors. In particular, there is little research on human-land and human-water binary relationships because of inadequate consideration of the multiple stress effects of human activities on the water environment, and indifference to the role of pollution control in improving regional water quality and controlling the effects of policy and market factors (Liu et al., 2010; Zuo and Zhao, 2009). Water resource and function zoning of the water environment must be considered on a national scale. Based on administrative regions or water function zones, the overall relationship between the water body and surrounding terrestrial ecosystem and socioeconomic system is fragmented in the nationwide approach. The existing management framework and basin zoning cannot effectively recon- 
cile the conflict and contradictions in water use among the upstream, midstream, and downstream regions, and the left and right banks of the HRB. Moreover, this framework and zoning cannot properly manage and guide the requirements for water quality, water ecology, and water environment management of different inter-administrative regional, trans-departmental, and cross-basin bodies (Chaves and Alipaz, 2007). Consequently, in examining the HRB as a case study, this work incorporates the water pollution prevention and control capacity (WPPC) into the water environmental supporting capacity (WESC) assessment system to develop a three-dimensional (3D) WESC model with the three dimensions of WECC, WEP, and WPPC relevant to the basin, based on the binary water cycle theory. The constraint mechanism of the water environment for economic development in the basin and spatial difference features among WECC, WEP, WPPC, and WESC are discussed and analyzed by using current data and methods. This study provides insights into improving the eco-balance, environmental protection, and industry direction of the basin, and avoids the limitations of previous research that evaluated basin management in terms of the water environment and the binary system of human activities.

\section{Study area}

The HRB region $\left(30^{\circ} 55^{\prime}-36^{\circ} 36^{\prime} \mathrm{N}\right.$ and $\left.111^{\circ} 55^{\prime}-121^{\circ} 25^{\prime} \mathrm{E}\right)$ is located in eastern China (Figure 1), between the Yellow River and the Yangtze River, the largest two rivers in China. It can be divided into the HRB and Yishusi River Basin, with the abandoned Yellow River as the dividing line. It is the seventh largest river basin in China, with a drainage area of 269,600 $\mathrm{km}^{2}$, covering 173 counties and cities (municipal districts) in Jiangsu, Anhui, Shandong, and Henan provinces (Zhou et al., 2013). The western part of the basin largely consists of hilly areas, and the rest of the basin consists of plains that cover about $2 / 3$ of the basin's total. The average total amount of water resources in the basin is about 79.4 billion $\mathrm{m}^{3}$, whereas the water resource volume per capita is only $1 / 5$ and $1 / 20$ of the national and global averages, respectively. In 2012, the basin had a total gross domestic product (GDP) of $40.06 \times 10^{4}$ billion RMB yuan, a total population of 181 million, a population density of 672 per $\mathrm{km}^{2}$

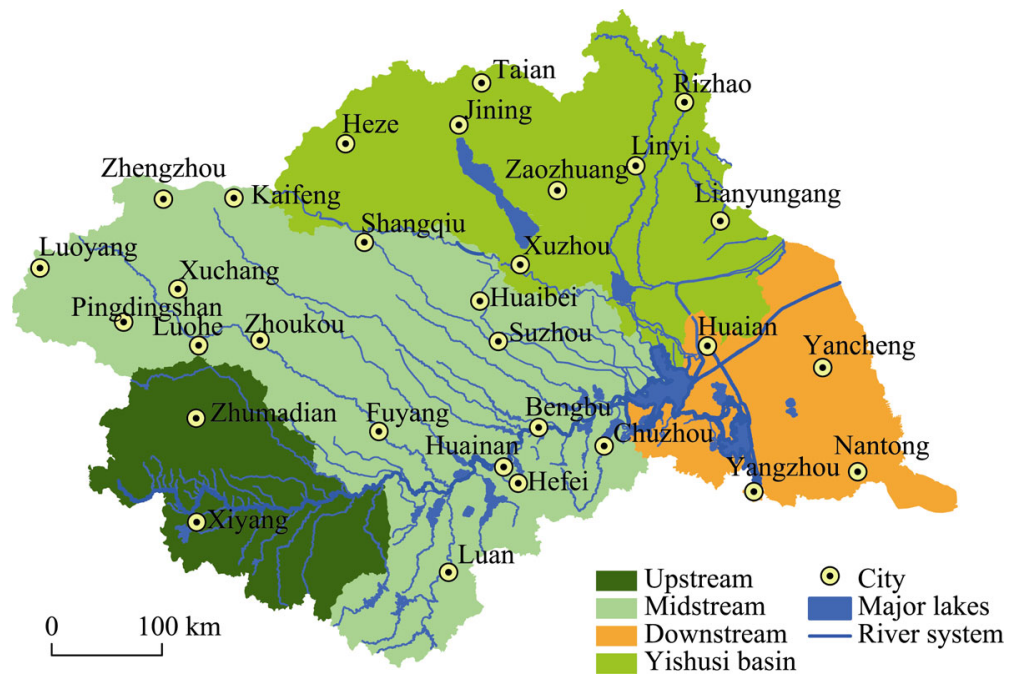

Figure 1 Location of the Huaihe River Basin 
(4.7 times the Chinese national average and 15.5 times the global average), and an urbanization rate of $35.91 \%$ (far below the Chinese national average of $52.57 \%$ ). The basin plays a strategically important role in the national industrial undertaking and transfer, coal production, and increase in agricultural production. In 2010, the grain production of the basin was $1083.51 \times 10^{8} \mathrm{~kg}$, accounting for $18.37 \%$ of the national grain output. The basin is also a major production area for wheat, maize, and rice. It is considered one of the core areas for increasing grain production in China, particularly to achieving an increase of $75 \times 10^{8} \mathrm{~kg}$ of grain. As an important industrial transitional zone for the economic region of the Yangtze River Delta, coal output in the basin accounts for about $1 / 8$ of the national total. Nonetheless, in the context of serious water pollution and complex issues surrounding the water environment, the basin currently experiences resource, quality, and structural water shortages. These three types of water shortages co-exist in some midstream areas of the basin. According to the 96 state-controlled water quality monitoring sections in the basin in 2010 , there are now 67 sections belonging to class IV or above, accounting for $68.4 \%$ of the total monitoring sections, of which 16 sections are worse than class $\mathrm{V}$. Thus, regulating water environmental pollution is an extremely challenging task.

\section{Data and research method}

\subsection{Data sources}

(1) Geographic data, including the vector diagrams of Levels I, II, and III substreams in the HRB, vector boundaries of the administrative divisions at the municipal and county levels, 57 water environment control units, high-precision digital elevation model (DEM) data for the HRB, vegetation coverage, 96 state-controlled monitoring sections, density of river networks, and other geographic spatial data, were mainly collected from a 1:250,000 map digitization of the Huaihe River purchased as required by the Huaihe River water project. (2) Data on the water resource and water environment; the chemical oxygen demand (COD) environmental capacity and $\mathrm{NH}_{4}{ }^{+}-\mathrm{N}$, emission load of $\mathrm{COD}$; monitoring values of the water quality sections; the quantity of water resources (surface water); urban sewage treatment rate; repeating utilization factor of industrial wastewater; standard-reaching rate of industrial wastewater; and other important data were obtained from regional bulletins (issued in 2010) of water resources for the HRB, the 2011 China Environment Yearbook, the 2011-2015 water pollution control plan in the key basins, and the official website of the Huaihe River Water Resources Commission. The data for the water environmental capacity were from 2008, while other data were from 2010. (3) Data on socioeconomic development were primarily acquired from the 2011 Statistical Yearbook of the 35 prefecture-level cities in the four provinces in the basin, the Statistical Yearbooks of villages (agriculture) in the four provinces, the 2011 China Livestock Yearbook, and the "12th Five-Year Plan" development reports and bulletins for each province and city in the basin. (4) In order to form a comprehensive research database for the water environmental economy in the HRB, diverse multi-scale fusion techniques are adopted to analyze the data, achieving a unified organization and integration of the spatial and statistical data on different scales. 


\subsection{Model building and research method}

\subsubsection{Construction of 3D model of supporting capacity (Figure 2)}

WECC is a concept that has limited uses. It is relevant to resource endowment, technological methods, and social choices and values. Moreover, WECC refers to a dynamic multifaceted relationship. The supporting role of the water environment in economic development is described by the three dimensions of WECC, WEP, and WPPC, which collectively affect the WESC. When WECC and WPPC are strong, the assimilative capacity of the water body is strong, the pollution supporting capacity generated from human activities is large, and the potential for regional development is high. In contrast, when WECC and WPPC are small, the assimilative capacity of the water body is limited, when WEP is large, the regional development is constrained. When WEP and WPPC change dynamically with the regional economic development level, management awareness, and policy factors, the carrying

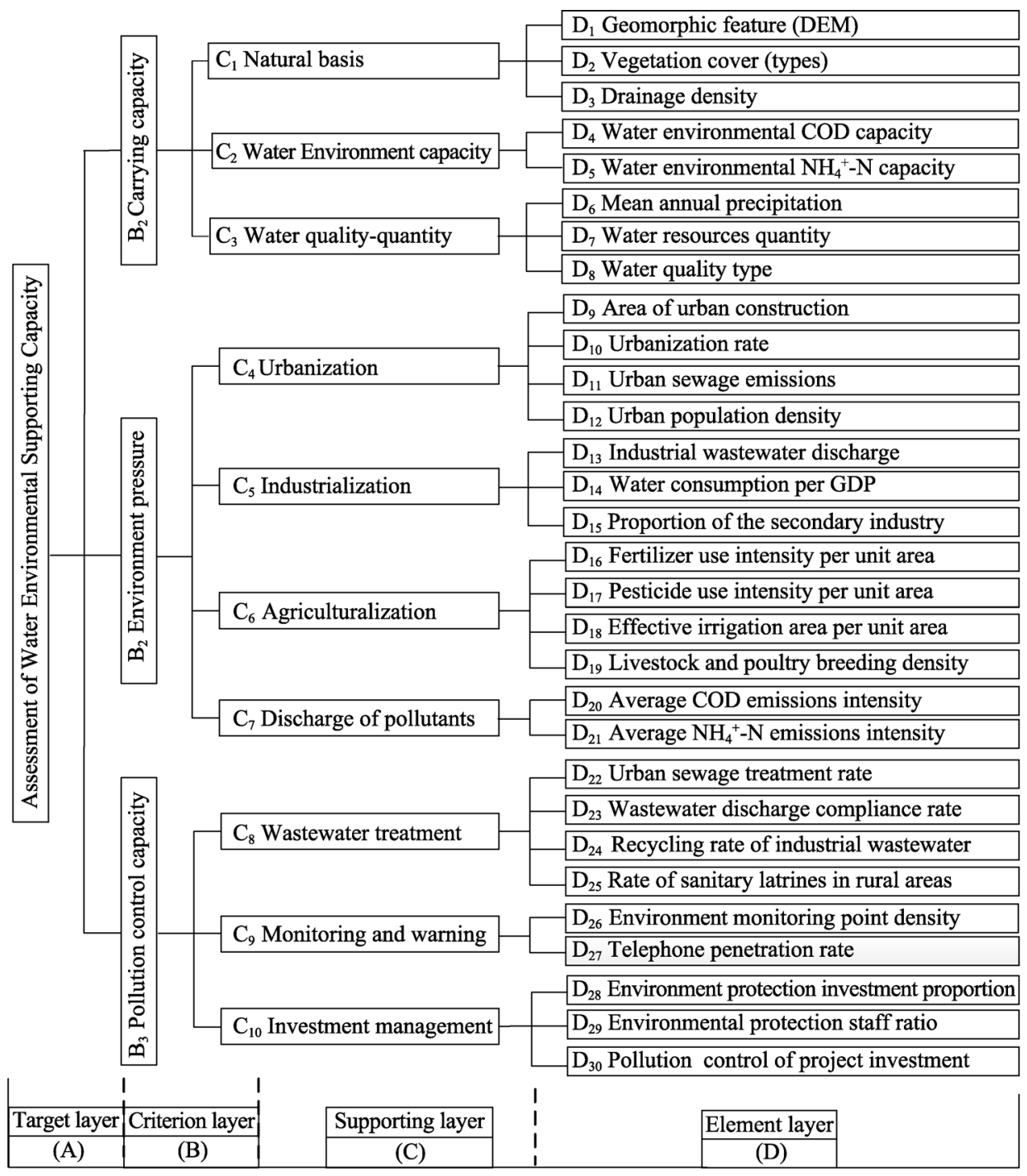

Figure 2 Schematic of WESC model for the Huaihe River Basin 
capacity of the water environment remains unchanged without external disturbances (e.g., water diversion outside the area). In this study, based on the principles of systematic, objectivity and independence, the latest data on these factors are gathered to form a 3D WESC dynamic assessment model of the HRB. The model can be divided into a target layer (A), a criterion layer (B), a supporting layer (C), and an element layer (D). Layer A refers to the basin WESC, and layer B contains the three dimensions of WECC, WEP, and WPPC. WECC covers the water environment capacity, water quality and volume, and natural features, and the assessment elements include the water environment capacity, water quality category, river network density, and geomorphic features. WEP represents the degree of stress that human activities place on the water environment, mainly from the total emission load of urbanization, industrialization, agricultural modernization, and sewage. For this dimension, there are 11 assessment elements, which include the urban construction land area, population density, emission load of COD and $\mathrm{NH}_{4}{ }^{+}-\mathrm{N}$, emission load of industrial wastewater and domestic sewage, livestock breeding density (standard pigs), and amount of fertilizer application. WPPC is generally determined by water pollution treatment, the level of monitoring and early warning, and the degree of input control. The assessment elements of this dimension include the town sewage treatment rate, compliance rate of discharge of industrial wastewater, the repeating utilization factor of the wastewater, the number of toilets in rural areas, the proportion of the environmental protection input in GDP, the proportion of people employed in environmental protection, and the predicted amount of investment in control programs. One of the key issues for comprehensive assessment is determining the index weight to obtain results that are more accurate. Based on the analytic hierarchy process method, this work makes judgments and comparisons according to the relationships and hierarchical structure relationship of the 3D WESC model. Judgment matrixes are used; for example, $\mathrm{A}-\mathrm{B}$ (the comparison and judgment matrix of second-grade index layer factors relative to the first-grade index layer), $B_{1}-C, B_{2}-C, B_{3}-C, B_{4}-C, C_{1}-D, C_{2}-D, \ldots, C_{10}-D$, etc. After a layer-by-layer calculation, we obtain the general ranking weight of the fourth-grade index layer (D) relative to the first-grade index layer (A) (Table 1).

Table 1 Fourth index weight ranking of WESC in the Huaihe River Basin

\begin{tabular}{cccccccccccc}
\hline Index & Weight & Index & Weight & Index & Weight & Index & Weight & Index & Weight & Index & Weight \\
\hline D1 & 0.051 & D6 & 0.029 & D11 & 0.053 & D16 & 0.039 & D21 & 0.033 & D26 & 0.015 \\
D2 & 0.028 & D7 & 0.076 & D12 & 0.057 & D17 & 0.010 & D22 & 0.007 & D27 & 0.008 \\
D3 & 0.093 & D8 & 0.066 & D13 & 0.021 & D18 & 0.025 & D23 & 0.024 & D28 & 0.014 \\
D4 & 0.019 & D9 & 0.016 & D14 & 0.034 & D19 & 0.008 & D24 & 0.034 & D29 & 0.031 \\
D5 & 0.038 & D10 & 0.010 & D15 & 0.027 & D20 & 0.065 & D25 & 0.031 & D30 & 0.036 \\
\hline
\end{tabular}

\subsubsection{Units of spatial evaluation}

The natural geographical zoning of HRB is obvious. However, the spatial units used in research need to be converted to county-level administrative regions to facilitate data combination and the environmental management. In this model, these objectives are achieved as follows. In ArcGIS10.2 (Redlands, CA, USA), the natural vector boundary of the HRB is superimposed on the vector boundary of the Chinese county-level administrative division in 2010. The principles for classifying the county-level administrative regions to the HRB are 
as follows. First, the proportion of the HRB accounting for the county territory is greater than $50 \%$; second, the proportion is less than $50 \%$, although the county-level administrative center is located in the basin; third, the proportion does not meet the first two conditions, but its ecological significance is high, because of water sources and important water resources. The municipal districts are integrated into one unit, and thus 173 counties (municipal districts) can be defined as the research scope for the HRB (Tang and Sun, 2012). The supporting capability evaluation of the water environment often uses the basin as the primary unit. In contrast, cities, counties, villages, and towns are used as the primary units in practical basin management and planning. The requirements for partition and planning are more effective when the factors for evaluating the WESC of the water environment in the basin are used as the primary unit, and then converted into 173 county administrative units with the polygon overlay analysis method. This step can unify the basin evaluation units and integrate the diverse multi-scale data. The conversion formula is

$$
C_{j}=\sum_{j=1}^{n} N_{j} \times A C_{i j} / A_{i}
$$

where $C_{j}$ is the WESC data of the administrative evaluation unit $i, A C_{i j}$ is the area of small basin $j$ in the administrative evaluation unit $i$ or water function area unit, $A_{i}$ is the total area of the administrative evaluation unit $i$, and $N_{j}$ is the WESC of small basin $j$ in administrative evaluation unit $i$ or water function area unit.

\subsubsection{Comprehensive evaluation model}

Based on single-factor analysis, 10 evaluation values of the supporting layer and three evaluation values of the criterion and target layers can be calculated by summing the values from the bottom to top levels with the weighting method. WEP is set as a single negative index (the lower the value, the higher the WESC), and WECC and WPPC are positive indices (the higher the value, the higher the WESC). The spatial distribution pattern, clustering, and internal relationships of the variable factors are indicated by classifying the evaluation factors of each layer with respect to the scientific experience and geographic information system (GIS) natural classification methods for breaking points. This can be expressed as

$$
W E P_{n}=\sum_{i=1}^{p} w_{i} e_{i} \quad(i=1,2 \ldots, n)
$$

where $W E P_{n}$ is the unit integrated value of index $n, p$ is the index of the next layer included by $n, W_{i}$ is the weight of $i$ index, and $e_{i}$ is the integrated value of $i$ index.

\section{Research results}

\subsection{Zoning assessment of WESC}

Comprehensive assessment of three dimensions water environmental supporting capacity (WESC) provides the scientific basis for industrial policies that are directed at harmonizing industrial development and water environmental supporting capacity.

\subsubsection{Zoning assessment of WESC}

According to Equation (1), 57 water environment control units and 96 river monitoring sec- 
tion spatial scale data points can be uniformly converted into 173 county-level administrative units with interpolation and polygon overlay methods. In particular, these conversion procedures can determine the index value of the eight factor layers. In the calculation, geomorphic (digital elevation model, DEM) and water quality classifications are processed as negative indices. WECC is further divided into eight levels (I-VIII) with Equation (2), and spatial statistical analysis is conducted to acquire the density of the river network, assimilative capacity, and distribution pattern of water quality classification in different regions. On this basis, three values of the supporting layer and WECC value can be calculated by integrating the classification values (I-VIII) of the factor layer to determine the spatial differences in WECC in the basin. The high WECC values (V-VII) mainly occur in the main stream of the Huaihe River, the Southern Anhui Plain to the south of the main stream, and the North Jiangsu Plain in the middle and lower reaches (Figure 3a). This region has a flat terrain, low elevation $(\leq 50 \mathrm{~m})$, abundant rainfall $(\geq 1000 \mathrm{~mm})$, and plentiful water resources. The river network is dense, and water distribution is excellent. In particular, the river in this region has a strong assimilative capacity. The environmental capacity for COD and $\mathrm{NH}_{4}{ }^{+}-\mathrm{N}$ is high, and the annual water quality ranges from class II to VI. The area in the high-value region accounts for $54.79 \%$ of the basin's total. The proportions of GDP (Gross Domestic Product), primary industrial output and secondary industrial output for the basin in this region are $50.39 \%, 52.37 \%$, and $46.57 \%$, respectively. The population of the area accounts for $47.60 \%$ of the basin population, implying that the WECC is high. Under these conditions, the very high WESC value areas (VIII) are generally distributed around Hongze Lake, Gaoyou Lake, and Chengdong Lake, with the main stream surrounding the border of Jiangsu and Anhui. In these areas, there is a high density of natural lakes, and the water system is well developed. The proportions of the area, population, and GDP of the very high WESC value areas are $1.62 \%, 10.02 \%$, and $11.92 \%$, respectively (Table 2 ). This suggests that this region has the highest WECC. Meanwhile, the low WECC value areas (I-IV) are generally located in sub-basins, including the Shaying River, Guohe River, and Huihe River to the north of the main stream of the Huaihe River. In these areas, the annual rainfall is relatively low, the river network is sparse, the extensive urban expansion interferes with many natural water systems, and the water environmental and assimilative capacities are relatively poor because the water self-purification capacity is low. Moreover, the water quality in these areas is frequently within the severe pollution status between Class A and Inferior Class V,

Table 2 Classification of water environmental carrying capacity in HRB in 2010

\begin{tabular}{lccccccccc}
\hline Classification & WEEC value & $\begin{array}{c}\text { District } \\
\text { (number) }\end{array}$ & $\begin{array}{c}\text { Land } \\
\text { area } \\
(\%)\end{array}$ & $\begin{array}{c}\text { Population } \\
(\%)\end{array}$ & $\begin{array}{c}\text { GDP } \\
(\%)\end{array}$ & $\begin{array}{c}\text { Agricultural } \\
\text { output (\%) }\end{array}$ & $\begin{array}{c}\text { Industrial } \\
\text { output }(\%)\end{array}$ & $\begin{array}{c}\text { Population } \\
\text { density } \\
\left(\text { person/ } / \mathrm{km}^{2}\right)\end{array}$ & $\begin{array}{c}\text { Livestock } \\
\text { density } \\
\left(\mathrm{pig} / \mathrm{km}^{2}\right)\end{array}$ \\
\hline I Lowest & $0.007-0.100$ & 14 & 5.65 & 8.59 & 10.39 & 6.50 & 11.85 & 1021.93 & 1668.19 \\
II Low & $0.101-0.120$ & 33 & 17.34 & 19.80 & 16.29 & 19.59 & 18.59 & 767.55 & 999.59 \\
III Lower & $0.121-0.140$ & 25 & 13.40 & 15.31 & 14.68 & 14.19 & 17.30 & 768.26 & 1018.58 \\
IV Low side & $0.141-0.155$ & 14 & 8.09 & 8.24 & 7.07 & 6.58 & 6.59 & 684.70 & 938.81 \\
V High side & $0.156-0.180$ & 23 & 13.25 & 13.90 & 13.44 & 12.00 & 13.61 & 704.97 & 951.85 \\
VI Higher & $0.181-0.200$ & 20 & 15.16 & 11.74 & 8.51 & 10.41 & 6.01 & 520.50 & 627.85 \\
VII High & $0.201-0.225$ & 25 & 14.75 & 11.94 & 17.07 & 18.93 & 16.06 & 544.03 & 588.53 \\
VIII Highest & $0.226-0.300$ & 15 & 11.62 & 10.02 & 11.92 & 11.03 & 9.36 & 579.49 & 597.61 \\
\hline
\end{tabular}


and the value of WECC is low.

\subsubsection{Zoning assessment of WEP}

In the basin, WEP is mainly represented by the discharge of industrial and domestic wastewater, discharge of pollutants from agricultural livestock, poultry breeding, pesticides, and fertilizers and soil nutrients. The WEP values of different areas in the basin can be obtained with Equation (2), and used to discuss its geographical variation. The high WEP value areas (V-VII) are mainly distributed in the North Jiangsu Plain and Shandong hills on the east coast of the basin, and in the central plain economic core regions in the northwest of the ba$\sin$ (Figure 3b). In these areas, the economy is developed, the population density is high, and modernization levels of urbanization, industrialization, and agriculture are higher than those of the other areas of the basin. The levels of COD, ammonia, and total phosphorous-to-total-nitrogen ratios are increasing, induced by the discharge of industrial and domestic pollutants, resulting in dangerous WEP for the water environment. The area in the high WEP value region accounts for $37.76 \%$ of the basin's total. The proportions of GDP, population, agricultural acreage, agriculture, and industry in this region are $61.78 \%, 42.96 \%$, $40.20 \%, 46.57 \%$, and $68.81 \%$, respectively. The population density is $765 \mathrm{per} / \mathrm{km}^{2}$ and the livestock and poultry breeding density is 960 standard pig $/ \mathrm{km}^{2}$ (Table 3). Intense human activity excessive development and urban expansion have resulted in a huge WEP increase for the water environment, and WEP in some areas at the maximum level. The large WEP of the water environment may be contributed by the following two reasons. (i) The majority of high WEP value areas are located in the center of the economic zone in the central plain and
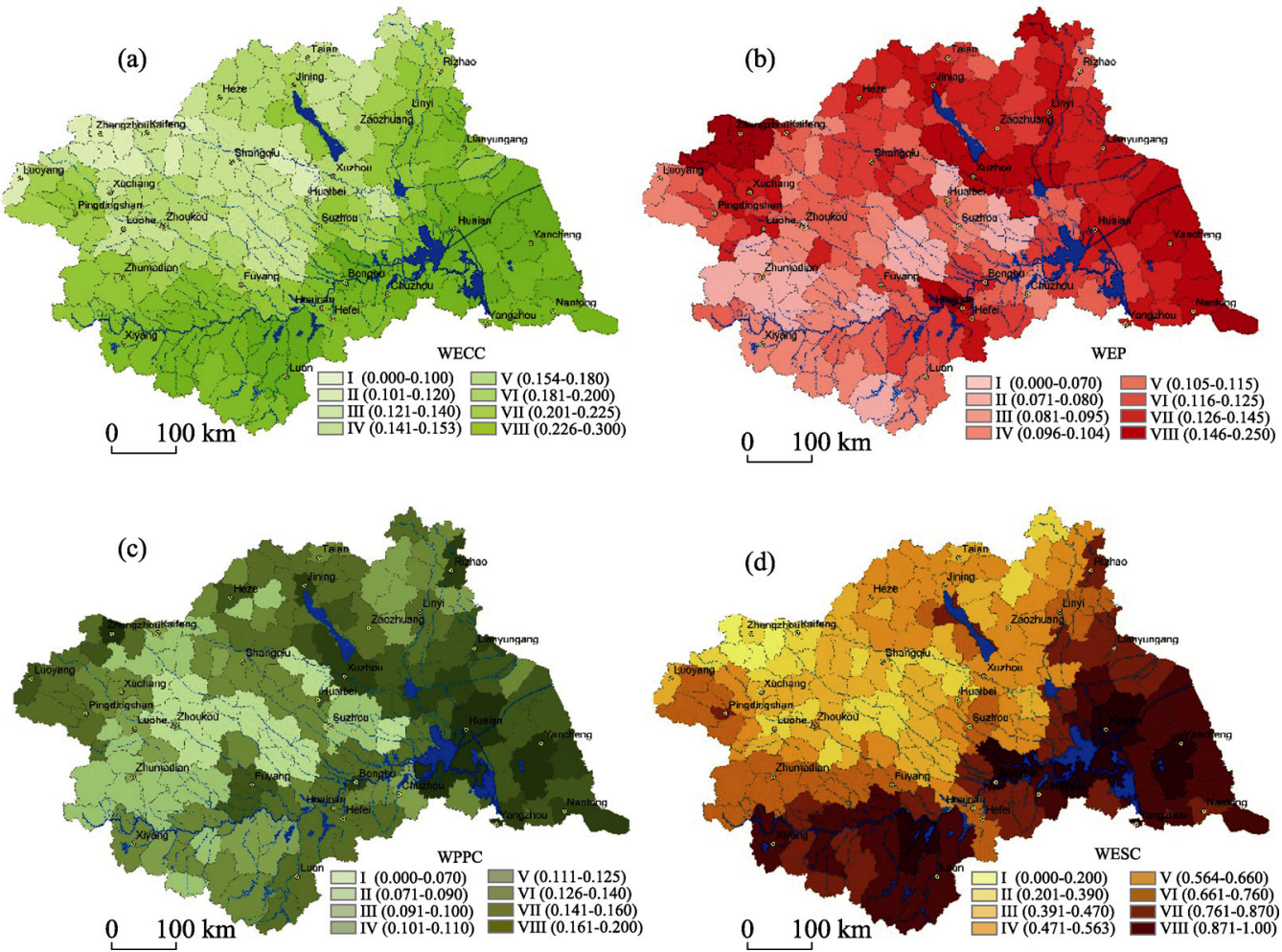

Figure 3 Classification of WESC in the Huaihe River Basin in 2010 
Table 3 Classification of WEP in the Huaihe River Basin in 2010

\begin{tabular}{lccccccccc}
\hline Classification & WEP value & $\begin{array}{c}\text { District } \\
(\text { number })\end{array}$ & $\begin{array}{c}\text { Land } \\
\text { area } \\
(\%)\end{array}$ & $\begin{array}{c}\text { Population } \\
(\%)\end{array}$ & $\begin{array}{c}\text { GDP } \\
(\%)\end{array}$ & $\begin{array}{c}\text { Agricultural } \\
\text { output }(\%)\end{array}$ & $\begin{array}{c}\text { Industrial } \\
\text { output }(\%)\end{array}$ & $\begin{array}{c}\text { Population } \\
\text { density } \\
\left(\text { person/ } \mathrm{km}^{2}\right)\end{array}$ & $\begin{array}{c}\text { Livestock } \\
\text { density } \\
\left(\mathrm{pig} / \mathrm{km}^{2}\right)\end{array}$ \\
\hline I Lowest & $0.007-0.100$ & 19 & 11.94 & 9.41 & 4.03 & 9.09 & 3.21 & 529.79 & 774.61 \\
II Low & $0.101-0.120$ & 21 & 13.84 & 12.23 & 7.91 & 10.80 & 6.23 & 594.08 & 658.24 \\
III Lower & $0.121-0.140$ & 33 & 18.83 & 18.80 & 13.54 & 17.96 & 10.70 & 670.82 & 907.37 \\
IV Low side & $0.141-0.155$ & 30 & 17.62 & 16.60 & 12.73 & 15.59 & 12.14 & 633.17 & 805.07 \\
V High side & $0.156-0.180$ & 28 & 15.33 & 17.54 & 23.60 & 20.92 & 25.41 & 769.05 & 795.03 \\
VI Higher & $0.181-0.200$ & 18 & 8.97 & 9.45 & 12.61 & 10.66 & 14.60 & 707.56 & 1020.95 \\
VII High & $0.201-0.225$ & 16 & 10.31 & 10.38 & 16.19 & 12.06 & 14.91 & 676.87 & 755.34 \\
VIII Highest & $0.226-0.300$ & 8 & 3.15 & 5.59 & 9.38 & 2.93 & 12.79 & 1194.10 & 2262.44 \\
\hline
\end{tabular}

the national industrial undertaking and transfer zone. The Yangtze River Delta urban agglomerations and Shandong peninsula economic zone are playing an important radiation role in this region. Moreover, the level of urbanization, industrialization, and economic development is higher than that of the other areas. (ii) These areas are directly benefitted from the industrial transfer. Several pollutants are also transferred because of the industrial transfer for regional development, resulting in new challenges to the WEP of the water environment.

\subsubsection{Zoning assessment of WPCC}

There are numerous problems in the upstream, downstream, and left and right banks of the basin, and in the different administrative regions. These water pollution concerns include water resource allocation, transboundary contamination, eco-compensation, and emissions and water rights trading. Many factors affect WPPC. This work includes the water pollution control processing technology; monitoring and early warning for emergencies and water pollution crises; management and supervision of the government, the public, media, and non-governmental organization (NGOs); and investment in preventing and regulating pollution to evaluate WPPC efficiently, based on scientific selection of indexes. The WPPC is evaluated by focusing on management and supervision, investment in prevention, and wastewater treatment research, monitoring, and early warning. The high-value areas of the basin are mainly distributed in the North Jiangsu Plain and Shandong Hill on the east coast of the basin. Bounded by the eastern route of the South-to-North Water Diversion, most high-value areas of the basin are located in the eastern region, whereas the majority of the low-value areas are situated in the western region (Figure 3c). The area in the high-value region accounts for $48.24 \%$ of the basin's total. The proportions of GDP, population, agricultural acreage, agriculture, and industry of the basin in this region are $66.49 \%, 51.32 \%$, $48.92 \%, 51.86 \%$, and $66.80 \%$, respectively. The population density is $714 \mathrm{per} / \mathrm{km}^{2}$ and the livestock and poultry breeding density is 806 standard pig $/ \mathrm{km}^{2}$ (Table 4). The differences in WPPC over the entire basin are obvious, in which most of the region has significantly development potential and space. By performing a further spatial comparison among the areas within the basin, when the region, including its environment, has higher WPPC, its economy can be developed efficiently, the people in the area may be more environmentally aware, and the market regulation system can be comprehensively improved. Finally, when media su- 
pervision in the area is more effective and transparent, government regulation and the use of anti-pollution funds within the area can be increased. In less developed areas, the WEP of the environment is low, and the environmental awareness of the public is low. Moreover, these areas are characterized by imperfect supervision and management, and limited investment, reducing the WPPC.

Table 4 Classification of water pollution prevention and control in the Huaihe River Basin in 2010

\begin{tabular}{lccccccccc}
\hline Classification & WPPC value & $\begin{array}{c}\text { District } \\
\text { (number) }\end{array}$ & $\begin{array}{c}\text { Land } \\
\text { area } \\
(\%)\end{array}$ & $\begin{array}{c}\text { Population } \\
(\%)\end{array}$ & $\begin{array}{c}\text { GDP } \\
(\%)\end{array}$ & $\begin{array}{c}\text { Agricultural } \\
\text { output }(\%)\end{array}$ & $\begin{array}{c}\text { Industrial } \\
\text { output }(\%)\end{array}$ & $\begin{array}{c}\text { Population } \\
\text { density } \\
\left(\text { person/ } \mathrm{km}^{2}\right)\end{array}$ & $\begin{array}{c}\text { Livestock } \\
\text { density } \\
\left(\mathrm{pig} / \mathrm{km}^{2}\right)\end{array}$ \\
\hline I Lowest & $0.007-0.100$ & 18 & 10.18 & 12.25 & 5.86 & 11.48 & 4.19 & 809.18 & 950.11 \\
II Low & $0.101-0.120$ & 22 & 12.24 & 10.72 & 7.88 & 12.19 & 6.73 & 588.51 & 1171.63 \\
III Lower & $0.121-0.140$ & 16 & 9.31 & 8.04 & 6.20 & 7.73 & 6.39 & 580.85 & 736.17 \\
IV Low side & $0.141-0.155$ & 33 & 20.04 & 17.76 & 13.56 & 16.74 & 13.77 & 595.78 & 805.69 \\
V High side & $0.156-0.180$ & 41 & 22.15 & 21.23 & 21.95 & 18.18 & 25.62 & 644.23 & 946.11 \\
VI Higher & $0.181-0.200$ & 21 & 13.31 & 14.39 & 15.62 & 14.47 & 14.40 & 726.76 & 793.94 \\
VII High & $0.201-0.225$ & 11 & 7.09 & 7.50 & 15.08 & 7.71 & 14.27 & 710.92 & 652.96 \\
VIII Highest & $0.226-0.300$ & 8 & 5.68 & 8.11 & 13.83 & 11.49 & 14.63 & 958.69 & 480.40 \\
\hline
\end{tabular}

\subsubsection{Zoning assessment of WESC}

Based on the zoning evaluation, WESC can be calculated and developed, the zones can be evaluated, and the types of region can be classified. The proportion of the WESC high-value regions in the basin increases. Thus, the WESC of $56.24 \%$ of the areas within the basin satisfies the requirements for economic development. However, a clear conflict between people and water exists in the remaining areas. Therefore, the water environment cannot continue to support the socioeconomic development of these areas. The water environment should be managed and regulated, and development should be limited or stopped to protect the water environment. The high-value regions account for proportions of $52.45 \%$ of GDP, $48.84 \%$ of the population, $52.02 \%$ of the agricultural acreage, $52.88 \%$ of agriculture, and $45.43 \%$ of industry in this region. The population density is $624 \mathrm{per} / \mathrm{km}^{2}$ and the livestock and poultry breeding density is 502 standard pig/ $\mathrm{km}^{2}$ (Table 5). The high-value areas of the basin are primarily distributed in the downstream region, the main stream region, and most regions in

Table 5 Classification of WESC in the Huaihe River Basin in 2010

\begin{tabular}{lccccccccc}
\hline Classification & WESC value & $\begin{array}{c}\text { District } \\
(\text { number) }\end{array}$ & $\begin{array}{c}\text { Land } \\
\text { area } \\
(\%)\end{array}$ & $\begin{array}{c}\text { Population } \\
(\%)\end{array}$ & $\begin{array}{c}\text { GDP } \\
(\%)\end{array}$ & $\begin{array}{c}\text { Agricultural } \\
\text { output }(\%)\end{array}$ & $\begin{array}{c}\text { Industrial } \\
\text { output }(\%)\end{array}$ & $\begin{array}{c}\text { Population } \\
\text { density } \\
\left(\text { person/ } / \mathrm{km}^{2}\right)\end{array}$ & $\begin{array}{c}\text { Livestock } \\
\text { density } \\
\left(\mathrm{pig} / \mathrm{km}^{2}\right)\end{array}$ \\
\hline I Lowest & $0.007-0.100$ & 4 & 1.61 & 1.58 & 3.53 & 1.70 & 5.45 & 659.20 & 3272.20 \\
II Low & $0.101-0.120$ & 20 & 9.04 & 12.51 & 12.33 & 10.19 & 14.30 & 929.99 & 1035.29 \\
III Lower & $0.121-0.140$ & 29 & 14.87 & 17.47 & 11.88 & 18.58 & 12.71 & 789.39 & 1024.36 \\
IV Low side & $0.141-0.155$ & 33 & 18.23 & 19.61 & 19.81 & 16.66 & 22.11 & 722.88 & 940.02 \\
V High side & $0.156-0.180$ & 25 & 13.70 & 14.30 & 13.59 & 11.85 & 10.59 & 702.04 & 1125.59 \\
VI Higher & $0.181-0.200$ & 25 & 15.20 & 12.98 & 12.33 & 12.82 & 12.15 & 573.97 & 607.21 \\
VII High & $0.201-0.225$ & 24 & 19.32 & 14.11 & 13.90 & 15.09 & 11.34 & 490.78 & 528.79 \\
VIII Highest & $0.226-0.300$ & 11 & 8.02 & 7.44 & 12.63 & 13.12 & 11.35 & 623.62 & 502.13 \\
\hline
\end{tabular}


the south of the main stream (Figure 3d).

There are distinct differences among the south and north banks, and the upstream, midstream, downstream, and Yishusi River stream of the basin. Furthermore, the WESC of the basin is higher on the south bank of the main stream than that of the north bank, whereas the downstream is higher than the upstream and midstream. The WESC of the upstream is higher; the proportions of high- and low-value areas are $86.71 \%$ and $14.29 \%$, respectively. The WESC of the downstream relatively is the highest, and the entire administrative region is in the high WESC value area. The midstream and Yishusi River stream have low WESC values (Figures 4 and 5).

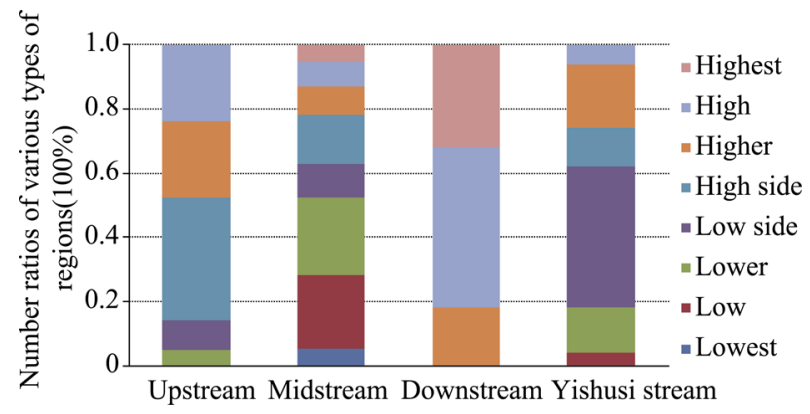

Figure 4 Number ratios of various types of regions among the upper, middle, down and Yishusi stream of the Huaihe River Basin based on supporting capacity

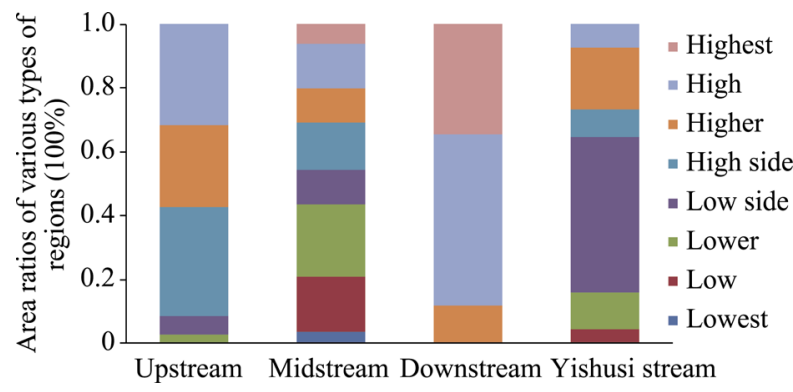

Figure 5 Area ratios of various types of regions among the upper, middle, down and Yishusi stream of the Huaihe River Basin based on supporting capacity

\subsection{Partition guidance for HRB industries}

The Huaihe River-Qinling Mountains boundary is important for China. The northern and southern sides of the Huaihe River show enormous differences in air temperature, rainfall, vegetation type, ecological landscape, resources and environment, production methods, and lifestyle. The distribution and regulation of industry differentiation can be clearly managed. Water environmental protection and pollution prevention can be positively managed by representing the WESC of the basin in 3D space by using the WECC, WEP, and WPPC values of each unit as the $X, Y$, and $Z$ axes, respectively. Moreover, these objectives can be achieved by using the higher and lower critical points of the index as the origin of the $X, Y$, and $Z$ axes according to the principle of the 3D model. Finally, the coordinate system can be divided into eight in intervals and eight types of industry (Figure 6 and Table 6). The spatial features of WECC, WEP, and WPPC of each unit can be precisely presented to guide 
Table 6 Zoning types of capacity of water environment in the Huaihe River Basin

\begin{tabular}{cccccccccc}
\hline $\begin{array}{c}\text { Zoning } \\
\text { types }\end{array}$ & $\begin{array}{c}\text { District } \\
\text { (num- } \\
\text { ber })\end{array}$ & $\begin{array}{c}\text { Land } \\
\text { area } \\
(\%)\end{array}$ & $\begin{array}{c}\text { Popu- } \\
\text { lation } \\
(\%)\end{array}$ & $\begin{array}{c}\text { GDP } \\
(\%)\end{array}$ & $\begin{array}{c}\text { Agricul- } \\
\text { tural } \\
\text { output }(\%)\end{array}$ & $\begin{array}{c}\text { Industrial } \\
\text { output } \\
(\%)\end{array}$ & $\begin{array}{c}\text { Population } \\
\text { density } \\
\left.\text { (person/ } / \mathrm{km}^{2}\right)\end{array}$ & $\begin{array}{c}\text { Livestock } \\
\text { density } \\
\left(\mathrm{pig} / \mathrm{km}^{2}\right)\end{array}$ & $\begin{array}{c}\text { Representative } \\
\text { region }\end{array}$ \\
\hline H-H-H & 33 & 19.07 & 21.21 & 31.46 & 27.52 & 30.97 & 747.49 & 1955.80 & Yangzhou, Haian \\
H-H-L & 5 & 2.58 & 2.12 & 2.05 & 2.42 & 2.37 & 552.25 & 1144.01 & $\begin{array}{l}\text { Fengtai, } \\
\text { Xiangshui }\end{array}$ \\
H-L-L & 12 & 5.34 & 5.94 & 7.03 & 5.88 & 9.25 & 746.90 & 1415.89 & $\begin{array}{l}\text { Kaifeng, Yishui } \\
\text { H-L-H }\end{array}$ \\
\hline L-L-H & 19 & 9.78 & 12.59 & 20.45 & 9.71 & 25.24 & 865.03 & 1155.03 & $\begin{array}{l}\text { Zhengzhou, } \\
\text { Fengxian }\end{array}$ \\
L-H-H & 21 & 14.39 & 11.57 & 9.82 & 10.13 & 7.48 & 540.51 & 558.94 & $\begin{array}{l}\text { Shouxian, } \\
\text { Gaoyou }\end{array}$ \\
L-H-L & 25 & 19.47 & 13.15 & 8.23 & 13.08 & 6.40 & 453.81 & 710.23 & $\begin{array}{l}\text { Fengyang, } \\
\text { Tongbai }\end{array}$ \\
L-L-L & 44 & 22.42 & 25.86 & 14.14 & 25.61 & 12.34 & 775.46 & 959.33 & Cixi, Linbi \\
\hline
\end{tabular}

Note: H: high, L: low. For example, H-H-H represents high WECC, high WEP, and high WPCC.

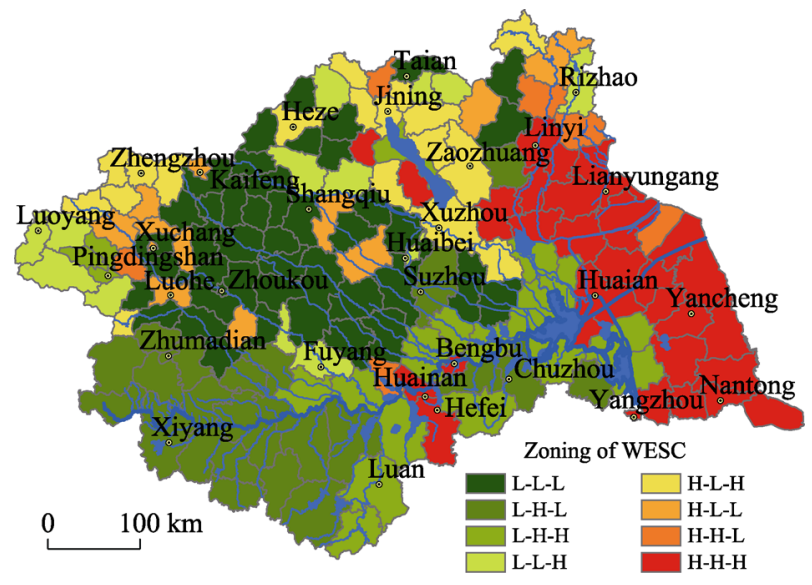

Figure 6 Zoning types of water environmental supporting capacity in the Huaihe River Basin

industrial development in the basin. The zoning types classified by the WECC, WEP, and WPPC values are described below. (Note that H: high, L: low. For example, H-H-H represents high WECC, high WEP, and high WPCC).

(1) H-H-H. In this type of area, the values of WECC, WEP, and WPPC are high, and the high-quality water environment and large investment in preventing pollution have supported economic development. These areas, which are mainly distributed in the downstream of the basin and to the west of the eastern route of the south-to-north water diversion project, have an area, GDP, and industrial output of $19.07 \%, 31.46 \%$, and $30.97 \%$, respectively, of the basin. The industrial distribution of these areas should be optimized and their industrial structure should be refined. Moreover, the use of pesticides and fertilizers in these areas should be strictly controlled to protect the water environment. Meanwhile, the food processing, textile and garments, biomedicine, machinery and electronics, and modern organic agriculture industries of these areas can be developed. (2) H-H-L. The development speed of this type of area is faster than that of the areas where speed of pollution prevention, and their 
subsequent security for supporting development are poor. (3) H-L-L. These areas have high WECC, WEP and WPPC are poor. This type of area accounts for 5.34\% of the basin's total, and the proportions of GDP and industrial output value are $7.03 \%$ and $9.25 \%$, respectively. Accordingly, for this type of area whose development largely depends on water diversion or groundwater exploitation, further disordered exploitation should be limited. The standards for environmental access and emissions should be improved. The wastewater treatment equipment in these areas should also be upgraded. Clean production and soil testing for formulated fertilization should be implemented, and eco-tourism, low-carbon agriculture, and other low-pollution industries should be developed to realize coordinated development between water environment and economy. (4) H-L-H. The values of WEP and WPPC of this type of area are higher, whereas their WECC value is lower. Consequently, the cost of developing water environment in these areas is high, and relies heavily on investment in preventing water pollution. The H-L-H areas are principally distributed in economic zones, such as Zhengzhou, Luoyang, and Xuzhou in the central plain, in which the manufacturing industries are concentrated. This type of area accounts for $9.78 \%$ of the basin's total, and the proportions of GDP and industrial output value are $20.46 \%$ and $25.24 \%$, respectively. The high WEP of the water environment in this area is caused by the expansion of urbanization, water resource shortages, and overload of water environmental capacity. In these areas, ecological, agricultural, and industrial water use should be coordinated; the structure and distribution of the three industries should be optimized; the carrying capacity of the water environment should be promoted by investing in and practicing water conservancy; the population size should be controlled; the water industry should be rapidly upgraded; fish breeding and poultry raising must be integrated; the textile printing and dyeing, rubber and plastic, petroleum chemical industries, and other high-polluting enterprises should be limited. In addition, the culture and education, transport and logistics, machinery manufacturing, electronic information, and other high- and new-technology industries should be developed. (5) L-L-H. The values of WEP and WECC of this type of area are lower, whereas the WPPC is higher. L-L-H areas account for $9.78 \%$ of the basin's total. In these areas, the direction of investment and the scale of industry should be optimized; the current leading industry chain should be established and promoted; and the coal power, wine brewing and food, textile and garment, and ceramic building materials should be developed in restricted clusters. (6) L-H-H. The WEP of this type of area is poor, and the WECC and WPPC are higher. These areas are chiefly situated in Shouxian, downtown Bengbu, and Gaoyou on the two sides of the main stream of the midstream and downstream regions of the Huaihe River. This type of area accounts for $14.39 \%$ of the basin's total, and the proportions of GDP and industrial output value are $9.82 \%$ and $7.48 \%$, respectively. The development potential of this type of area is clear. For long-term environmental control, part of these areas should not be developed to ensure that the water quality of the main stream of the Huaihe River remains satisfactory. Nevertheless, even with strict enforcement of the environmental impact assessment, these areas still have considerable development potential. Based on the existing industrial foundations, projects conforming to the national industry policy and the requirements of industrial development should proceed, and an industrial transfer platform that connects with the Yangtze River Delta should be formed to limit the industry transfer zone in Anhui and Jiangsu. Thus, new energy resources, food processing, automotive assembly, coal elec- 
tricity, building materials, and chemical industry can be developed. (7) L-H-L. The values of WEP and WPPC of this type of area are lower, whereas the WECC is higher. These areas are mainly around the source and upstream of the Huaihe River. This type of area accounts for $19.47 \%$ of the basin's total. These areas cannot be developed extensively because they consist of many mountains and hills. Therefore, based on their good water environment and ecology, the scale and location of agriculture of these regions should be optimized, and eco-tourism, aquaculture, grain and oil processing, and other clean industries should be developed. (8) L-L-L. The values of WEP, WECC, and WPPC of this type are low. These areas are primarily distributed in most regions in Anhui and Henan, which are located south of the main stream. This type of area accounts for $22.42 \%$ of the basin's total, and the proportions of GDP and industrial output value are $14.14 \%$ and $12.34 \%$, respectively. Based on point and nonpoint source pollution, the agricultural planting structure of these counties should be adjusted to reduce water environmental pollution caused by fertilizers and pesticides, and farmers should be helped to plant efficient drought-resistant crops, and optimize water resource allocation, manufacturing, and electricity consumption. Modern agriculture with low water and energy consumption should also be developed within this sector by conforming to the hierarchy of protection, prevention, and development, thereby encouraging and promoting investment of pollution control in the private sector.

\section{Conclusions and discussion}

\subsection{Research conclusion}

The HRB is an area that has been substantially altered by human activities. In this region, the conflict between water and humans is serious because of increasing long-term pollution and excessive development. This issue requires urgent resolution to curb the continuing deterioration of the water environment to achieve sustainable development of the socioeconomy and water environment. This work serves as a basis for planning and managing the distribution of industry in the basin and protection of the water environment, through the construction of a 3D WESC model. This model is intended to guide the economic development of the water environment based on understanding the relationship between humans and water, scientific assessment of the WESC partition, and classification of the areas of the basin. The following conclusions can be drawn from the results obtained in this research.

(1) The WECC of the HRB shows large geographical variation. The high WECC areas account for $54.79 \%$ of the basin's total. They are mainly located to the east of the eastern route of the South-to-North Water Diversion, south of the Huaihe River, and the lakes and wetlands on the Jiangsu-Anhui border that have plenty of water resources (e.g., Weishan, Hongze, and Gaoyou Lakes). The upper sub-basins (e.g., Shayin, Huihe, and Honghe Rivers) have a low carrying capacity because they experience less rainfall. Overlapping characteristics can be observed between the basin WEP and WPPC spatial distributions. Areas with a large WEP also have a large WPPC, and vice versa. The high-value areas account for $37.76 \%$ and $48.24 \%$ of the basin's total, and they are primarily situated in the downstream areas with high population densities, high industrialization, urbanization, and modern agriculture. These areas also include the hinterland of the central plains economic zone in the northwest of the basin (e.g., Zhengzhou, Kaifeng, and Luoyang). The large area to the south 
of the basin headstream, upstream, and mainstream has smaller WEP, with a relatively small WPPC.

(2) The WECC of the HRB shows large differences between the south and the north, and among the three regions. The area with high WESC only accounts for $56.24 \%$ of the basin's total. The high-value areas are mainly located in plains, rivers, and lakes with good water access in the downstream, with abundant water resources, advanced economic development, and good pollution prevention. Meanwhile, the low-value areas are located in the midstream region. These regions suffer from shortages of resources, poor water quality, and structural water shortages, and rely on overexploitation of the groundwater to maintain a balance between supply and demand.

(3) Based on the WEP, WECC, and WPPC, industry should be located in the area east of the eastern route of South-to-North Water Diversion (less restricted by the water environment) and in the area south of the mainstream (improved natural carrying capacity of the water environment). For the midstream and Yishusi River basin, particularly in Zhengzhou, Kaifeng, and Luoyang in the economic zones of the central plains, local industries should be upgraded; the development of severe pollution industries, such as textile, dyeing, petroleum, chemical, and paper, should be strictly constrained; industrial capacity should be gradually eliminated; and clean, low-pollution industries should be developed. In these areas, the water environment capacity is saturated. The upstream and water resources of the basin, important sources of drinking water, the eastern route of the South-to-North Water Diversion, and ecologically fragile areas must be protected or only limited development allowed to ensure a good water environment and provide a clean water supply.

\subsection{Discussion}

This paper discusses the supporting role of the water environment for improving the HRB from the perspective of the WECC, WEP, and WPPC. Compared with previous studies, the current research uses a segmental assessment system for WPPC. The combination of multivariate multi-scale data allows the multiple environmental factors to be converted into administrative division units. This research also considers emerging new problems, such as basin industrial pollution transfer, the increase in nonpoint source pollution, basin development priorities, and the coordination mechanisms and competition relationship among the regions of the basin. The results of this research are consistent with the practice of the HRB, and provide practical guidance for coordinating the further development of the basin water environment and economy. Data access restrictions mean that the existing index system does not include drinking water resources, biodiversity, soil, and water loss for assessing the WECC, policy coordination factors (e.g., eco-compensation), and outward water transfer for the WPPC assessment.

\section{References}

Cai X, 2008. Water stress, water transfer and social equity in northern China: Implications for policy reforms. Journal of Environmental Management, 87(1): 14-25.

Chaves H M L, Alipaz S, 2007. An integrated indicator based on basin hydrology, environment, life, and policy:

The watershed sustainability index. Water Resources Management, 21(5): 883-895.

De Mouche L, Landfair S, Ward F A, 2011. Water right prices in the Rio Grande: Analysis and policy implications. 
Water Resources Development, 27(2): 291-314.

Dong Y, Liu Y, Chen J N, 2014. Will urban expansion lead to an increase in future water pollution loads? A preliminary investigation of the Haihe River Basin in northeastern China. Environmental Science and Pollution Research, 21(11): 7024-7034.

Hering D, Borja A, Carstensen J et al., 2010. The European Water Framework Directive at the age of 10: A critical review of the achievements with recommendations for the future. Science of the Total Environment, 408(19): 4007-4019.

Jiang Y, 2009. China's water scarcity. Journal of Environmental Management, 90(11): 3185-3196. (in Chinese)

Kallis G, Butler D, 2001. The EU water framework directive: Measures and implications. Water Policy, 3(2): $125-142$.

Li F Y, Liu W D, Tang Z P, 2013. Study on inter-regional transfer of embodied pollution in China. Acta Geographica Sinica, 68(6): 791-801. (in Chinese)

Li J Y, Li L J, 2012. Water resources supporting capacity to regional socio-economic development of China. Acta Geographica Sinica, 67(3): 410-419. (in Chinese)

Liu J H, Qin D Y, Wang H et al., 2010. Dualistic water cycle pattern and its evolution in Haihe River Basin. Chinese Science Bulletin, 55(16): 1688-1697.

McMahon G, Gregonis S M, Waltman S W et al., 2001. Developing a spatial framework of common ecological regions for the conterminous United States. Environmental Management, 28(3): 293-316.

Mylopoulos Y A, Kolokytha E G, 2008. Integrated water management in shared water resources: The EU Water Framework Directive Implementation in Greece. Physics and Chemistry of the Earth, Parts A/B/C, 33(5): $347-353$.

Nian Y Y, Li X, Zhou J et al., 2014. Impact of land use change on water resource allocation in the middle reaches of the Heihe River Basin in northwestern China. Journal of Arid Land, 6(3): 273-286. doi: 10.1007/s40333-013-0209-4

Omernik J M, 1987. Ecoregions of the conterminous United States. Annals of the Association of American Geographers, 77(1): 118-125.

Ouyang T P, Zhu Z Y, Kuang Y Q, 2006. Assessing impact of urbanization on river water quality in the Pearl River Delta Economic Zone, China. Environmental Monitoring and Assessment, 120(1-3): 313-325.

Ren L, Cui E, Sun H, 2014. Temporal and spatial variations in the relationship between urbanization and water quality. Environmental Science and Pollution Research, 21(7): 13646-13655.

Singh A K, Tripathy R, Chopra U K, 2008. Evaluation of CERES-Wheat and Cropsyst models for water-nitrogen interactions in wheat crop. Agricultural Water Management, 95(7): 776-786.

Snelder T H, Biggsbarry J F, 2002. Multiscale river environment classification for water resources management. Journal of the American Water Resources Association, 38(5): 1226-1239.

Soendergaard M, Jeppesen E, Peder Jensen J et al., 2005. Water Framework Directive: Ecological classification of Danish lakes. Journal of Applied Ecology, 42(6): 616-629.

Sun W, Chen W, Chen C et al., 2011. Constraint regionalization of water environment and the guidance for industrial layout: A case study of Jiangsu Province. Journal of Geographical Sciences, 21(5): 937-948.

Tang C C, Sun W, 2012. Comprehensive evaluation of land spatial development suitability of the Yangtze River Basin. Acta Geographica Sinica, 67(12): 1587-1598. (in Chinese)

Tian D, Zheng W, Wei X et al., 2013. Dissolved microcystins in surface and ground waters in regions with high cancer incidence in the Huaihe River Basin of China. Chemosphere, 91(7): 1064-1071.

Yu S T, Huang X J, Chen X C et al., 2009. Initial allocation of pollution discharge rights: A case study in Huaihehe River Basin. Resources Science, 31(7): 1175-1180. (in Chinese)

Wang C, Zhu D S, Chen X B, 2002. Surface water function regionalization system. Journal of Hehai University: Natural Sciences, 30(5): 7-11. (in Chinese)

Wang D X, Wang H, Ma J, 2000. Water resources supporting capacity for regional development in China. Journal of Hydraulic Engineering, 11(11): 21-26. (in Chinese)

Xia J, Zhang Y Y, Zhan C et al, 2011. Water quality management in China: The case of the Huaihe River Basin. 
Water Resources Development, 27(1): 167-180.

Xia Q, 1989. Regionalization of the Water Environmental Protect Function Areas. Beijing: China Ocean Press. (in Chinese)

Xie R, Pang Y, Li Z et al., 2013. Eco-compensation in multi-district river networks in north Jiangsu, China. Environmental Management, 51(4): 874-881.

Yang A M, Tang K W, Wang H et al., 2008. Eco-hydrological regionalization in China. Journal of Hydraulic Engineering, 39(3): 332-338. (in Chinese)

Yang G, Zhuang D, 2014a. Atlas of the Huaihe River Basin Water Environment: Digestive Cancer Mortality. Springer Science \& Business Media.

Yang G, Zhuang D, 2014b. Research on the correlation between cancer and the Huaihe River water environment. In: Atlas of the Huaihe River Basin Water Environment: Digestive Cancer Mortality. Springer Netherlands, $1-26$.

Zhang H, Huang G H, 2011. Assessment of non-point source pollution using a spatial multicriteria analysis approach. Ecological Modelling, 222(2): 313-321.

Zhang X, Zhuang D, Ma X et al., 2014. Esophageal cancer spatial and correlation analyses: Water pollution, mortality rates, and safe buffer distances in China. Journal of Geographical Sciences, 24(1): 46-58.

Zhang Z Q, Cheng L, Shang H Y et al., 2012. Review and trend of eco-compensation mechanism on river basin. Acta Ecologica Sinica, 32(20): 6543-6552. (in Chinese)

Zhao H X, Jiang X B, 2013. Evolution of economic and industrial pollution gravity centers and the decoupling mechanism in Yangtze River. China Environmental Science, 33(10) 1911-1919. (in Chinese)

Zhou F, Liu Y, Huang K et al., 2007. Water environmental function zoning at watershed scale and its key problems. Advances in Water Science, 18(2): 216-222. (in Chinese)

Zhou L, Xu J G, Sun D Q et al., 2013. Spatial heterogeneity and classified control of agricultural non-point source pollution in Huaihe River Basin. Environment Science, 34(2): 547-554. (in Chinese)

Zuo Q T, Jin R F, Xia J et al., 2014. China pursues a strict water resources management system. Environmental Earth Sciences, 72(6): 2219-2222.

Zuo Q T, Zhao C X, 2009. Discussion on game theory research framework and key problems of human-water harmony. Journal of Natural Resources, 24(7): 1315-1324. (in Chinese) 